\title{
LOCALISAÇÕES ERRÁTICAS DO "PARASCARIS EQUORUM" (GOEZE, 1782) NO CORAÇÃO DO CAVALO E "ASCARIS LUMBRICOIDES" L., 1758 NAS VIAS BILIARES DO CARNEIRO E MESENTÉRIO DE CRIANÇA
}

POR

\section{Cesar Pinto e Z. Vaz \\ Com 4 estampas}

Tivemos recentemente a oportunidade de estudar dois casos interessantes de localisação errática de Ascarídeos de animais domésticos: o Parascaris equorum (Goeze, 1782) e o Ascaris lumbricoides L., 1758, esta última espécie foi encontrada em carneiro (Ovis aries) facto de ocorrência pouco frequente.

No coração de um cavalo morto no Instituto Butantan foi encontrado ao se abrir o ventrículo esquerdo, um exemplar macho de $\mathrm{Pa}$ rascaris equorum (sin.: Ascaris megalocephala) disposto no sentido longitudinal (Fot. 1), com a extremidade posterior atravessando a válvula aurículoventricular e a extremidade anterior penetrando profundamente na musculatura do ventrículo na região do ápice do coração, como se póde ver na fotografia n. ${ }^{\circ}$. E' dificil explicar como um helminto de tais dimensões possa atingir a cavidade do ventrículo esquerdo, introduzindo ainda profundamente a região cefálica na possante musculatura do orgão. A hipótese mais razoavel é a de que a larva, ao fazer o ciclo pulmonar, em vez de perfurar o alvéolo para atingir a traquéia e depois o intestino, voltou pelas veias pulmonares ao coração esquerdo, localisando-se no ventrículo esquerdo. $\mathrm{O}$ helminto em questão foi identificado ao Parascaris equorum pelo aspecto da extremidade cefálica, muito caracteristico. Os espículos mediam apenas 2,3 milímetros de comprimento, mostrando tratar-se de um exemplar que ainda não atingira o desenvolvimento completo, pois, nesta espécie os espículos medem cêrca de 4 milímetros.

A fotografia n. ${ }^{\circ} 2$ mostra um fígado de carneiro em cujo canal colédoco se pode ver cinco exemplares incompletamente desenvolvidos de um Ascarídeo que examinados microscopicamente mostraram pertencer á espécie Ascaris lumbricoides.

Sobre a localisação errática de ovos de A. lumbricoides no mesentério de criança referimos aqui a observação inédita de Oswino Penna.

«No Serviço de Anatomia Patológica do Hospital Pronto Socorro da Assistência Municipal do Rio de Janeiro tivemos oca- 
sião de autopsiar um caso muito interessante do ponto de vista das localisações erráticas de ovos de Ascaris lumbricoides.

Damos a seguir uma descrição resumida do caso.

Foi recolhido ao serviço cirúrgico do Dr. Adair de Figueredo um menino de 12 annos com sintomas de abdomen agudo, não muito graves, mas como fossem duradouros e não se modificassem, resolveu o Dr. Figueredo laparatomisar o doentinho verificando um tumor com as dimensões de u'a mão fechada no mesentério, aderente ás alças intestinais. Procuramos cuidadosamente perfuração intestinal com a prova de água e não encontramos. Pelo aspecto macroscópico pensamos em linfadenite tuberculosa mesentérica ou neoplasma. Colhemos material para histopatologia e verificamos um processo inflamatório não especifico constituido por algumas células gigantes de corpo extranho, linfócitos e células plasmáticas e células endotelióides (Mallory); em porções mais limitadas o processo inflamatório era mais agudo, mostrando exsudato de polinucleares, hemátias e fibrina.

Ficamos sem explicação justificavel para êste processo inflamatório. Percorrendo outros córtes deparamos com um ovo de Ascaris lumbricoides (Est. 3) perfeitamente diagnosticavel, envolvido pelos elementos celulares do processo inflamatório acima descrito.

Não é facil imaginar como se processou a imigração destes ovos.

Nas paredes do intestino e no parênquima hepático (Cirrose hépatica parasitária) temos observado esta imigração a longas distâncias dos vasos, parecendo-nos que se trate de imigração passiva, determinada pela movimentação dos tecidos.» Oswino PENNA.

\section{ABSTRACT}

The authors observed a male specimen of Parascaris equo$r u m$ in the left heart ventricle of Equus caballus. The parasite shows its posterior end passing through the auriculo-ventricular valve, while its anterior extremity is deeply sunk in the muscular layer of the left ventricle.

Reporting the presence of Ascaris lumbricoides in the ductus choledochus of Ovis aries, the authors also refer to an unpublished observation of OswiNo PENNA, who found eggs of this worm in the inflammatory tissue of the mesenterium of a child, in $a$ case of acute abdomen, without intestinal perforation. 
Aos Drs. J. B. Arantes, do Instituto Butantan e Samuel Pessôa, da Faculdade de Medicina de S. Paulo, agradecemos a oferta das peças que serviram de base ao presente trabalho e que se acham depositadas no laboratório de Parasitologia da Faculdade de Medicina Veterinaria da Universidade de S. Paulo.

\section{BIBLIOGRAFIA}

BAylis, H. A. - 1929 - A Manual of Helminthology Medical and Veterinary. London. pp. $128-134$

Cameron, TH. W. M. -- 1934 - The Internal Parasites of Domestic Animals. A Manual for Veterinary Surgeons. London. pp. 122-128.

FAUST, E. C. - 1929 - Human Helminthology. A Manual for clinicians, sanitarians and medical zoologists. Philadelfia. Lea \& Febiger, ed.

Goodey, T. - 1926 - On the Ascaris from Sheep. Jour. of Helminthol. 4 (1), 1-6, figs. 1-3.

YoRKe, W. \& MAPlestone, P. A. - 1926 - The Nematodes Parasites of Vertebrates. London. pp. 254-262. 


\section{EXPLICAÇÃO DAS ESTAMPAS}

Est. 1 - Coração de Equus caballus mostrando um exemplar macho de Parascaris equorum no ventrículo esquerdo. A seta inferior mostra a extremidade cefálica do helminto fóra da cavidade ventricular. B. Mazza, fot.

Est. 2 - Fígado de Ovis aries mostrando cinco exemplares de Ascaris lumbricoides no canal choledoco. B. Mazza, fot.

Est. 3 - Fotomicrografia de ovo de Ascaris lumbricoides encontrado em tecido inflamatório do mesentério de criança, em caso de abdomen agudo, sem perfuração intestinal. Original de Oswino Penna.

Est. 4 - Apice do coração de Equus caballus cortado longitudinalmente para mostrar a extremidade cefálica do Parascaris equorum introduzida no músculo cardíaco. 


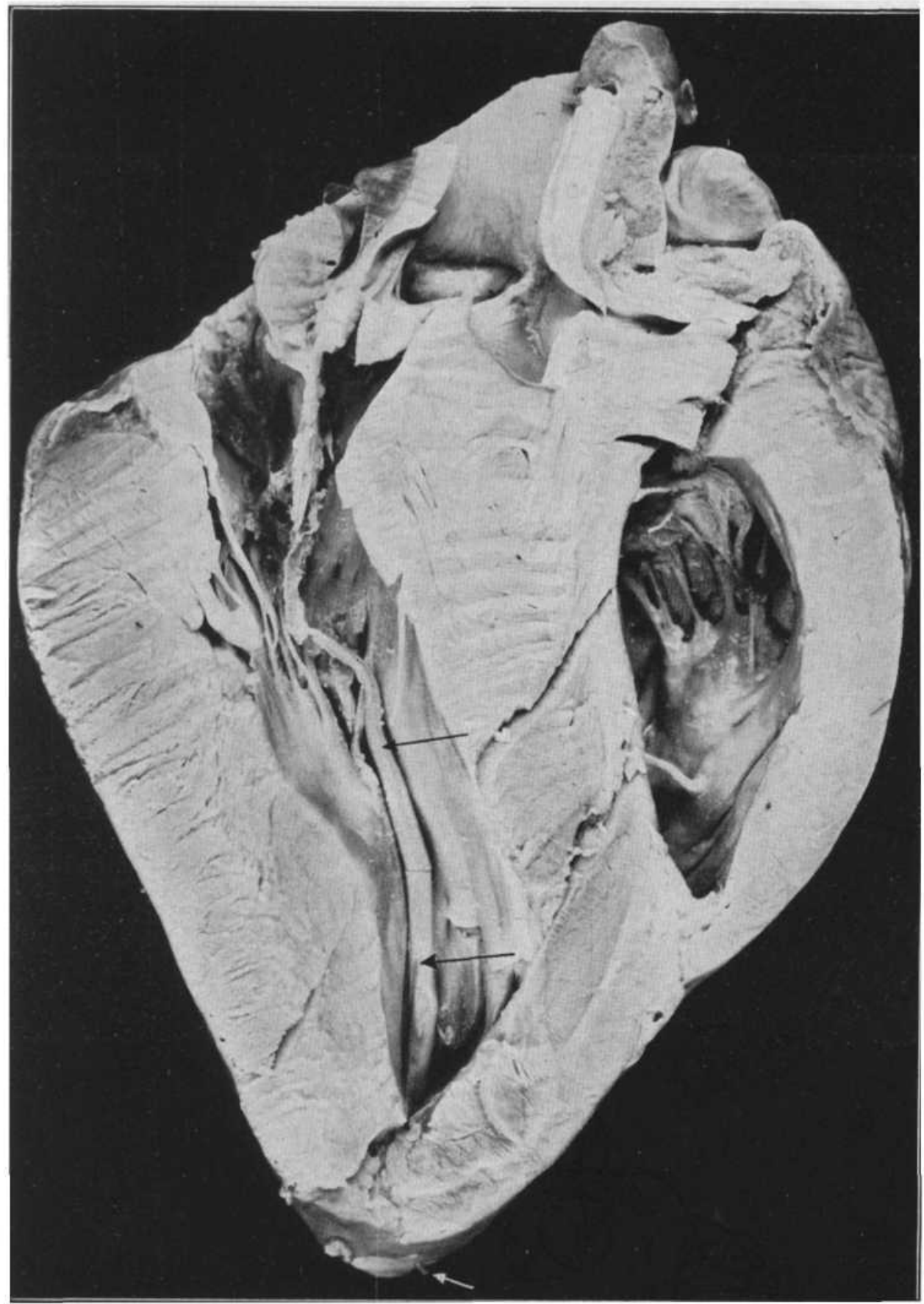




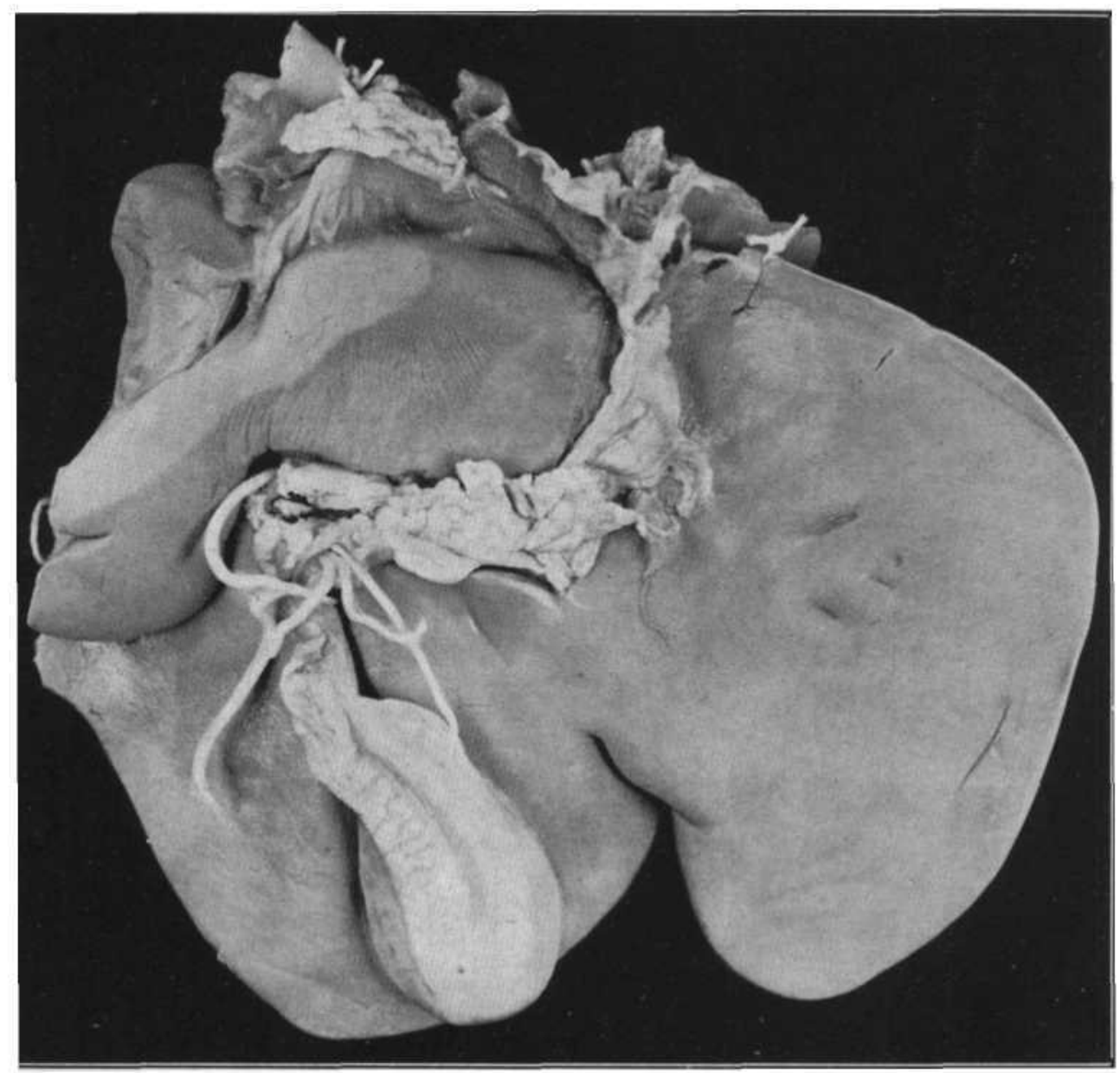




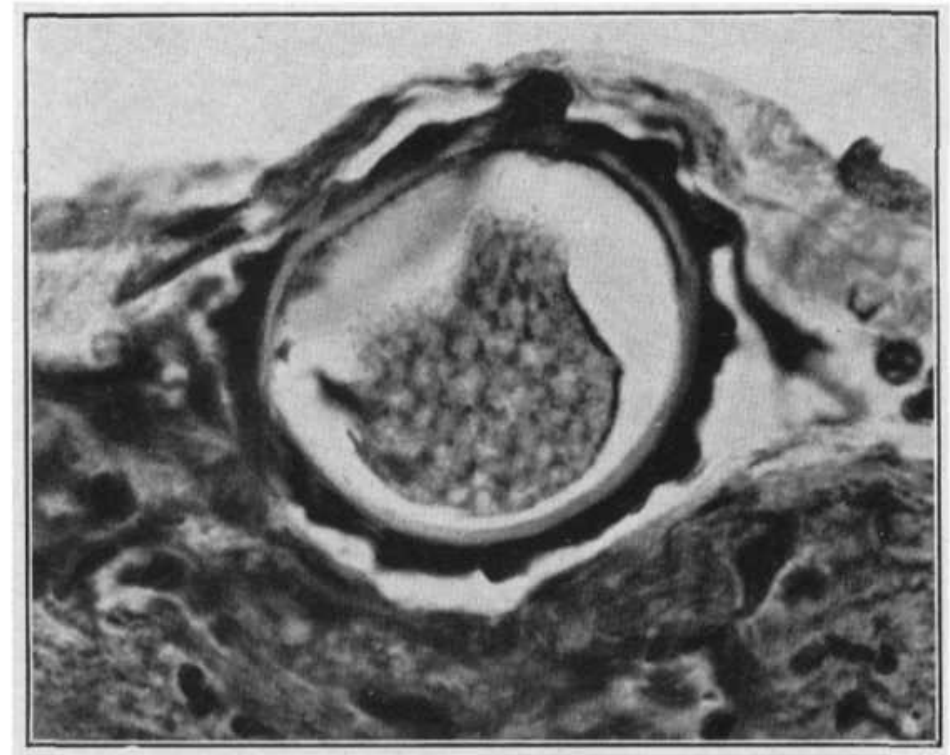

3

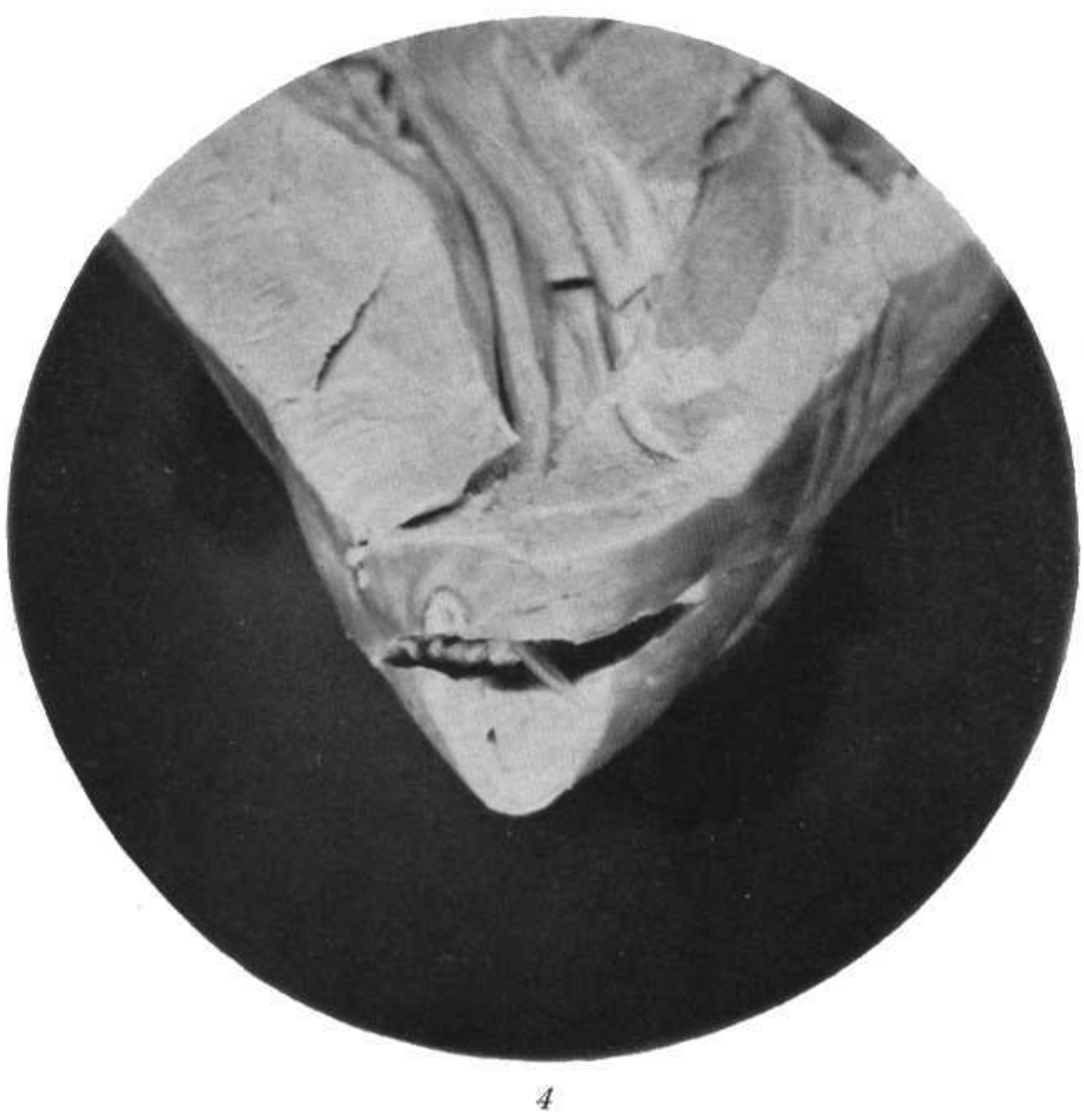

